American Medical Journal 3 (2): 147-160, 2012

ISSN 1949-0070

(C) 2012 Science Publications

\title{
Gynaecologic Nephrology
}

Naheed Ansari, Jolina Santos, Fuad Spath and Srujana Polsani

Department of Medicine, Division of Nephrology, Jacobi Medical Center, Albert Einstein College of Medicine, Bronx, 10461, New York

\begin{abstract}
Renal issues are commonly encountered in females. They can occur both in pregnant and nonpregnant females. Many physiologic changes occur during pregnancy to accommodate the growing fetus. Pregnancy is characterized by changes in blood pressure and expansion of total body volume which results in high glomerular filtration rate. The common renal problems seen in pregnant females are hypertension, proteinuria with or without nephrotic syndrome, acute kidney injury. It is not uncommon to see a pregnant female who may have pre-existing chronic kidney disease. A very few women receiving dialysis become pregnant. Renal transplantation restores the infertility seen in chronic kidney disease. Renal transplant recipients with pregnancy require very close monitoring of immunosuppressive medications to prevent acute rejection due to altered drug absorption and metabolism in pregnancy. Uterine fibroids are commonly encounters in women of reproductive age. Nonpregnant females with uterine fibroids usually experience non-renal symptoms like excessive uterine bleeding but few of them can develop hypertension, acute kidney injury and chronic kidney disease from uterine fibroids. Malignancies of female genital system can give rise to kidney failure when locally invasive. This review paper gives details of various renal problems seen by nephrologists in female patients both during pregnancy and nonpregnant states in daily practice.
\end{abstract}

Key words: Pregnancy, Uterine Fibroids, Renal Disease, Glomerular Filtration Rate (GFR), Vascular Endothelial Growth Factor (VEGF), Acute Kidney Injury Network (AKIN)

\section{INTRODUCTION}

A-renal disorders during pregnancy: This section will first review physiologic changes during pregnancy and then various disorders seen by nephrologists during pregnancy.

Renal physiology in pregnancy: Pregnancy is accompanied by many changes in the urinary tract. Both kidneys increase in size by $1-1.5 \mathrm{~cm}$ during pregnancy due to increase in renal vascular and interstitial volume (Bailey and Rolleston, 1971). There are no histological changes in the kidney but glomerular filtration rate increases.

The ureters and renal pelvis undergo dilatation in many pregnant women under effect of progesterone particularly in primigravida (Rasmussen and Nielsen, 1988; Beydoun, 1985). This dilatation is more prominent on right side than the left. The dilated collecting system can hold 200-300 cc of urine. This dilatation of urinary tract is visible on renal ultrasound by the second trimester and can persist up to 12 weeks postpartum. Urinary bladder becomes edematous and hyperemic during pregnancy. Progesterone causes relaxation of the wall of the bladder which may lead to its increased capacity. The bladder can be displaced superiorly and anteriorly by the enlarged gravid uterus. Due to relaxation of bladder smooth muscles, there is incompetence of the vesicoureteral valve and it can result in intermittent vesicoureteral reflux (Mattingly and Borkowf, 1978; Heidrick et al., 1967). Pregnant women experience increased urinary frequency, nocturia, dysuria, urgency and stress incontinence (Thorp et al., 1999; Wesnes et al., 2007).

Glomerular Filtration Rate (GFR) increases in pregnancy due to rise in cardiac output and renal flow rate. Total peripheral vascular resistance decreases during pregnancy due to vasodilatation. It results from decreased responsiveness of vascular endothelium to vasoconstrictors (angiotensin, epinephrine and vasopressin) and increased production of vasodilators like nitric oxide. Blood volume increases in pregnancy due to activation of renin angiotensin system causing salt and water retention (Elsheikh et al., 2001). Total body water increases by 6-8 L leading to expansion of plasma and interstitial volumes. The increase in GFR

Corresponding Author: Naheed Ansari, Division of Nephrology, Department of Medicine, Jacobi Medical Center, Albert Einstein College of Medicine, Bronx, 10461, New York 
occurs within one month of the conception and reaches its peak in early second trimester. GFR increases usually by $40-50 \%$ over baseline and decreases slightly toward term (Davison and Dunlop, 1980).

Serum creatinine decreases during pregnancy due to high GFR and is usually $0.4 \mathrm{mg} \mathrm{dL}^{-1}$ lower than pregestation level. Renal function is usually monitored during pregnancy by measurement of serum creatinine. Normal value of serum creatinine during pregnancy is 0.4-0.6 $\mathrm{mg} \mathrm{dL}^{-1}$. Thus, a pregnant woman with serum creatinine of $1.0 \mathrm{mg} \mathrm{dL}^{-1}$ has significant impairment of renal function. $24 \mathrm{~h}$ urine collection for creatinine clearance is of limited accuracy in pregnancy (Cote et al., 2008). Urinary protein excretion increases in normal pregnancy to $200 \mathrm{mg} \mathrm{day}^{-1}$ in the third trimester due to rise in GFR. Serum uric acid declines in early pregnancy due to rise in GFR. It can be as low as 2-3 $\mathrm{mg} \mathrm{dL}{ }^{-1}$ by 24 weeks of gestation (Lind et al., 1984). After 24 weeks, uric acid level begins to rise and can reach non gestation level by term. Rise in serum uric acid in early pregnancy points to presence of renal disease. Hyperuricemia is frequently encountered in patients with preeclampsia.

Certain electrolyte and acid base changes can also be appreciated during pregnancy. Hyponatremia is frequently encountered in pregnancy. Serum sodium level is usually around $132-134 \mathrm{meq} \mathrm{L}^{-1}$ (Lindheimer et al., 1989). Hyponatremia is usually due to effect of relaxin on the brain. The ability to maintain osmoregulation via thirst and anti-diuretic hormone level is well maintained in pregnancy. Pregnant women suffer from chronic respiratory alkalosis due to increase in minute ventilation. This hypocapnia results from direct stimulation of respiratory center by progesterone (Lim et al., 1976). Partial pressure of carbon dioxide (pCO2) decreases to $27-32 \mathrm{~mm} . \mathrm{Hg}$ and is accompanied by compensatory increase in renal excretion of bicarbonate. There is small reduction in serum anion gap in pregnant women and can be detected throughout the pregnancy (Akbari et al., 2007). Tubular function in pregnancy is impaired and it manifests as glucosuria, aminoaciduria and increased urinary excretion of beta microglobulin. Placenta produces an enzyme, vasopressinase, which degrades vasopressin produced by pituitary gland. Increased activity of this enzyme can give rise to diabetes insipidus in some pregnant women. Table 1 classifies various renal problems seen commonly by nephrologists regarding female reproductive system.

Now this section will review various renal issues seen in pregnancy.

A-hypertensive disorders in pregnancy: Normal pregnancy is characterized by drop in blood pressure due to decrease in peripheral vascular resistance which results from generalized vasodilatation.
Table 1: Classification of renal disorders of female reproductive system Renal disorders of Female Reproductive System During Pregnancy

A-Hypertensive disorders of pregnancy

1-Chronic hypertension

2-Gestational hypertension

3-Preeclampsia

4-Preeclampsia superimposed on preexisting hypertension

B- Diabetes Insipidus

C- Acute Kidney Injury

D -Chronic Kidney Disease in pregnancy

E-Pregnant Patient with End Stage Renal Disease

F -Renal Transplant Recipient with pregnancy

In Non Pregnant Females

A-Uterine fibroids and malignancies of female reproductive system 1-Urinary Retention

2-Acute Kidney Injury

3-Chronic Kidney Disease

4-Hypertension

This is usually evident by 6 weeks of gestation and leads to an average drop in blood pressure of $10 \mathrm{~mm} . \mathrm{Hg}$ below non-pregnant levels by second trimester. Some pregnant women can develop hypertension during pregnancy. These hypertensive disorders are divided into four categories (Helewa et al., 1997). They are discussed below.

Chronic hypertension: It is presence of high systolic and diastolic blood pressure before onset of pregnancy or is present before 20th week of pregnancy at least on two occasions. It can persist longer than 12 weeks after delivery of the baby. Usually systolic blood pressure is $>140 \mathrm{~mm} . \mathrm{Hg}$ and/or diastolic blood pressure is $>90$ $\mathrm{mm} . \mathrm{Hg}$. Chronic hypertension can occur as result of number of medical disorders or can occur without any cause as idiopathic hypertension. Chronic hypertension is present in 3-5\% of pregnancies (Yoder et al., 2009; Magee et al., 1999). It is more common in obese, blacks and older maternal age. Pregnant women with chronic hypertension have an increased risk of preeclampsia and preterm delivery.

Gestational hypertension: It is new onset of hypertension in a previously normotensive pregnant female which occurs in last trimester of pregnancy usually around 32 weeks of pregnancy. It can occur in up to $6 \%$ of pregnancies (Yoder et al., 2009). There is no proteinuria and hypertension resolves usually by 12 weeks after delivery of the baby. Therefore reassessment at 12 weeks postpartum is required to make definite diagnosis. If hypertension persists after 12 weeks in postpartum period, the diagnosis is usually preexisting chronic hypertension which was masked in early during pregnancy due to vasodilatation. Gestational hypertension can recur in subsequent pregnancies (Hjartardottir et al., 2006). Gestational hypertension can progress to overt preeclampsia in 10$25 \%$ of cases (Wallis et al., 2008; Saudan et al., 1998). 
Am. Med. J. 3 (2): 147-160, 2012

Table 2: Risk factors for preeclampsia

\begin{tabular}{ll}
\hline Social and demographic Factors & Medical Factors \\
\hline Age $<18$ years or $>40$ years & Preeclampsia in previous pregnancy \\
Black race & Family history of preeclampsia \\
Woman with high body mass index & Chronic hypertension \\
Male partners whose mother or previous partner had preeclampsia & Chronic renal disease \\
Nulliparity & Vascular or connective tissue disease \\
Prolonged inter-pregnancy interval & Diabetes Mellitus \\
Partner related factors (new partner, limited sperm & Hydops fetalis \\
exposure such as with use of barrier contraception & \\
& Multifetal gestation \\
& Hydatidiform mole \\
& Genetic predisposition \\
& Antiphospholipid antibody syndrome or inherited thrombophilia \\
& Unexplained fetal growth restriction \\
\hline
\end{tabular}

Preeclampsia: It is defined as new onset of hypertension and proteinuria in a previously normotensive pregnant woman after 20 weeks of gestation. It can rarely occur before 20 weeks of gestation as seen in molar pregnancy. Preeclampsia is usually classified as mild or severe preeclampsia.

Eclampsia is characterized by onset of grand mal seizures in a woman with preeclampsia. The patient usually does not have any pre-existing history of any other neurologic conditions.

HELLP syndrome is severe form of preeclampsia and is characterized by hemolysis, elevated liver enzymes and low platelets. It can occur independent of presence of proteinuria and hypertension in $15-20 \%$ of patients (Reubinoff and Schenker, 1991).

Incidence of preeclampsia: Preeclampsia is seen in $7.5 \%$ of pregnancies throughout the world (Dolea and AbouZahr, 2003). Incidence varies depending upon maternal age and ratio of primigravida among populations (Hutchison et al., 2003). In the United States, preeclampsia and eclampsia account for $15-20 \%$ of all pregnancy related maternal mortality.

Risk factors for preeclampsia: A number of conditions can predispose pregnant woman to develop preeclampsia. These risk factors can be divided into social, demographic and medical risk factors (Table 2).

Pathogenesis of preeclampsia: Placenta plays a central role in pathogenesis of preeclampsia since delivery of placenta is associated with remission of the disease (Shembrey and Noble, 1995). Fetus is not needed for preeclampsia as preeclampsia can occur in case of hydatidiform mole. During early placental development fetal cytotrophoblast invades the uterine spiral arteries of the decidua and myometrium which results in their transformation from small resistance uterine vessels into flaccid low resistance, high caliber capacitance vessels (Wolf et al., 1980). This vascular transformation allows increase in uterine bold flow needed to sustain the fetus through pregnancy. This transformation is incomplete in preeclampsia (Robertson et al., 1967). Cytotrophoblast invasion of the arteries remains limited to superficial decidua and myometrial segments remain narrow and undilated (Meekins et al., 1994). In normal pregnancy, the developing cytotrophoblasts acquire endothelial cell surface adhesion phenotype called dubbed pseudovasculogenesis (Zhou et al., 1997). Certain angiogenic and antiangiogenic factors and receptors expressed by cytotrophoblast play a key role in the placental pseudovasculogenesis like Vascular Endothelial Growth Factor (VEGF), Placental Growth Factor (PlGF), soluble FMS-like tyrosine kinase 1(sFlt) which is also referred to as soluble VEGF receptor 1(sVEGFR1), Endoglin (a truncated form of a TGF beta receptor) and angiopoietin receptors TIE-1 and TIE-2. The local balance of these factors is of paramount importance in placental vasculogenesis. VEGF ligands and receptors are highly expressed by placental tissue in the first trimester (Yancopoulos et al., 2000). sFlt decreases cytotrophoblast invasiveness in vitro (Zhou et al., 2002). sFlt levels are very low in early pregnancy and rise towards end of pregnancy signaling termination of placental vasculogenesis. In preeclamptic women, sFlt levels are elevated very early during pregnancy and contribute to inadequate cytotrophoblast invasion in preeclampsia as seen in primigravida and twin pregnancies (Wolf et al., 2005; Bdolah et al., 2008). VEGF is important in the health of fenestrated and sinusoidal endothelium found in renal glomerulus, brain and liver, these organs are particularly affected in preeclampsia (Esser et al., 1998). VEGF is highly expressed by podocytes and glomerular endothelial cells (Simon et al., 1998). High circulating levels of sFlt in preeclampsia bind VEGF and PIGF in circulation leading to their decreased serum levels interfering with placental vasculogenesis and hence cause placental insufficiency.

Pathology: Renal pathology in preeclampsia is characterized by endothelial swelling called glomerular endotheliosis in which endothelial cells become swollen, 
develop vacuolization and lose their fenestrae. There is depositon of fibrinogen and fibrin within and under the endothelial cells. The podocyte foot processes are intact early during the disease but podocyturia is seen in preeclampsia and other high risk pregnancies (Jim et al., 2012). This glomerular endotheliosis is not pathognomonic to preeclampsia. Renal blood flow and GFR are low in preeclampsia due to high renal vascular resistance and decrease in ultrafiltration coefficient of glomerular capillaries due to endotheliosis. Systemic vasoconstriction results in high blood pressure. Women with preeclampsia have endothelial dysfunction which is present prior to onset of hypertension and proteinuria (Khan et al., 2005). This endothelial dysfunction persists for many years after preeclampsia (Chambers et al., 2001).

Long term epidemiological studies have shown increased prevalence of hypertension, diabetes mellitus, ischemic heart disease, ESRD, stroke and cardiovascular mortality in women with history of preeclampsia (McDonald et al., 2008; Bellamy et al., 2007).

Clinical features: Preeclampsia is characterized by hypertension which can be mild or severe, proteinuria $>300 \mathrm{mg} /$ day in $24 \mathrm{~h}$ urine collection, edema and hyperuricemia. The degree of proteinuria can vary and range from minimal to nephrotic range proteinuria. Preeclampsia is classified as mild or severe. Patient with proteinuria $>5$ grams per day is classified as severe preeclampsia. Hyperuricemia results from increased tubular reabsorption of uric acid.

Preeclampsia can progress from mild asymptomatic disease to life threatening illness called eclampsia and HELLP syndrome (an acronym for the syndrome of hemolytic anemia, elevated liver enzymes and low platelets). Clinical and laboratory findings help monitoring progression to severe disease. Severe hypertension (BP $>160 / 110 \mathrm{~mm} . \mathrm{Hg}$ ), nausea, vomiting, headaches, visual disturbances, altered mental status and parameters of fetal growth restriction should alarm to presence of severe preeclampsia. Pulmonary edema can occur in $2-3 \%$ of severe preeclampsia (Tuffnell et al., 2005). Seizures can occur in $2 \%$ of preeclamptic cases (Saftlas et al., 1990). Right upper quadrant pain or epigastric pain can point to liver injury. Laboratory findings include hemoconcentration, microangiopathic hemolytic anemia with elevated bilirubin and low haptoglobin levels, thrombocytopenia with platelet count $<100,000$, elevated liver enzymes, high serum creatinine and severe proteinuria $>5$ gram/day. In 10$15 \%$ of women with HELLP and severe eclampsia, it can occur without hypertension or proteinuria.

Treatment of preeclampsia: It includes absolute bed rest, prevention of seizures and prompt control of blood pressure if $\mathrm{BP}>150-160 / 100-110 \mathrm{~mm} . \mathrm{Hg}$ ) to reduce risk of cerebral hemorrhage (ACOG, 2002). The commonly used anti-hypertensive medications include calcium channel blockers, hydralazine and alpha methyldopa Use of angiotensin converting enzyme inhibitors, angiotensin receptor blockers, diuretics and beta blockers should be avoided. Other modalities to treat preeclampsia include administration of magnesium intravenously to prevent seizures. Serum magnesium levels should be monitored to avoid toxicity. The delivery of the baby depends on gestational period and signs and symptoms of severe preeclampsia. Termination of pregnancy is advisable in severe preeclampsia presenting prior to 24 weeks due to high maternal complication rate (Bombrys et al., 2008). In mild preeclampsia presenting between 24-34 weeks of gestation without any signs and symptoms, delivery can be postponed to allow for fetal maturity (Odendaal et al., 1990). Any woman with HELLP syndrome usually needs prompt delivery of the baby due to very high incidence of maternal complications. Intravenous steroids may be used for fetal maturity.

Some modalities for prevention of preeclampsia in high risk women include use of anti-platelet agents, calcium supplementations and use of antioxidants.

Preeclampsia superimposed on chronic hypertension: It is defined as onset of proteinuria and worsening blood pressure after 20 weeks of gestation in a woman with preexisting hypertension. The diagnosis of superimposed preeclampsia can be very difficult. In absence of underlying renal disease, the new onset of proteinuria (>300 mg/day) along with worsening hypertension can be defined as superimposed preeclampsia. In patients with preexisting proteinuria, a significant increase in blood pressure $>30 \mathrm{~mm}$. Hg over baseline along with other clinical and laboratory features such as high levels of liver function tests, thrombocytopenia and hemolysis signify preeclampsia. Treatment is on the same principles as discussed for preeclampsia.

Secondary hypertension in pregnancy: Hypertension in pregnancy can occasionally be due to causes like renal artery stenosis, primary hyperaldosteronism, hyperthyroidism and pheochromocytoma. Renal artery stenosis is usually fibromuscular in origin in most young pregnant females but atherosclerotic lesions may account for renal artery stenosis in older females. Diagnosis is suspected by presence of treatment resistant hypertension and can be confirmed by magnetic resonance imaging. It is usually treated with angioplasty and stent placement during second and third trimester of pregnancy (Hayashida et al., 2005). 
Table 3: Types of Diabetes Insipidus (DI) during Pregnancy

\begin{tabular}{|c|c|c|c|}
\hline Type of DI & Mechanism of DI & Treatment of DI & Special Features \\
\hline Gestational diabetes insipidus & Increased vasopressinase activity & $\begin{array}{l}\text { Desmopressin either nasally } \\
\text { or subcutaneously }\end{array}$ & $\begin{array}{l}\text { Does not recur in } \\
\text { subsequent pregnancies }\end{array}$ \\
\hline $\begin{array}{l}\text { Subclinical central or nephrogenic } \\
\text { Diabetes Insipidus }\end{array}$ & $\begin{array}{l}\text { Insufficient vasopressin level or } \\
\text { resistance to endogenous vasopressin }\end{array}$ & $\begin{array}{l}\text { Can be treated with vasopressin } \\
\text { analogs if central diabetes insipidus }\end{array}$ & $\begin{array}{l}\text { Symptoms present prior to } \\
\text { and after pregnancy }\end{array}$ \\
\hline $\begin{array}{l}\text { DI associated with } \\
\text { hepatic dysfunction }\end{array}$ & $\begin{array}{l}\text { Decreased degradation of vasopressinase } \\
\text { by hepatic dysfunction resulting in } \\
\text { increased activity of vasopressinase }\end{array}$ & $\begin{array}{l}\text { Desmopressin can be given for } \\
\text { treatment since it is resistant to } \\
\text { degradation by vasopressinase }\end{array}$ & $\begin{array}{l}\text { Usually seen in patients } \\
\text { with preeclampsia and } \\
\text { HELLP syndrome }\end{array}$ \\
\hline Miscellaneous & Deficiency of vasopressin & $\begin{array}{l}\text { Responds to administration of } \\
\text { vasopressin analogs }\end{array}$ & $\begin{array}{l}\text { Usually occurs in } \\
\text { postpartum period due } \\
\text { to severe bleeding causing } \\
\text { panhypopituitrism }\end{array}$ \\
\hline
\end{tabular}

Pheochromocytoma can be associated with high maternal and neonatal morbidity and mortality but usually is diagnosed at time of delivery due to onset of severe hypertensive crisis. Management involves timely attention to blood pressure control and surgery of the tumor is usually postponed after delivery if possible.

Primary hyperaldosteronism in pregnancy is usually suspected by presence of hypokalemia with hypertension. It can be due to presence of either an adrenal adenoma or bilateral adrenal hyperplasia. Circulating progesterone level can antagonize the hyperaldosteronism but it does not occur in every pregnant female necessitating treatment in others (Wyckoff et al., 2000). Surgical resection of the adrenal adenoma is usually deferred until after delivery.

Another cause of secondary hypertension during pregnancy is mineralocorticoid receptor mutation which is very rare. This disorder is caused by mineralocorticoid receptor activation by circulating progesterone during pregnancy and results in marked elevation of blood pressure during pregnancy. Usually, there is no proteinuria or other features of preeclampsia in affected females (Geller et al., 2000). Use of spironolactone can make control of blood pressure worse.

B-diabetes insipidus: aPregnancy is associated with changes in urinary frequency and nocturia. Rarely, polyuria (urine output more than $3 \mathrm{~L} /$ day) is encountered in pregnancy. Diabetes Insipudus is a rare occurrence in pregnancy and is characterized by polyuria and polydipsia (Durr, 1987). There are various causes of diabetes insipidus during pregnancy (Table 3 ).

a-Gestational diabetes insipidus: The incidence of diabetes insipidus is 2-4 cases per 100,000 gestations. Diabetes insipidus occurs due to increased degradation of Anti-Diuretic Hormone (ADH) by vasopressinase, an enzyme released from placenta (Durr et al., 1987; Lindheimer et al., 1991). ADH increases permeability of collecting tubules of the kidney to water. This is mediated through effect of $\mathrm{ADH}$ on $\mathrm{V} 2$ receptors located on renal collecting tubules resulting in formation of concentrated urine. $\mathrm{ADH}$ is metabolized by an enzyme called vasopressinase released by placenta during pregnancy (Durr et al., 1987). Vasopressinase activity increases during pregnancy peaking in the third trimester, remains high during labor and becomes undetectable after delivery of the baby in two to four weeks. Metabolic clearance of $\mathrm{ADH}$ increases four to six fold because of increased vasopressinase activity. Plasma $\mathrm{ADH}$ level remains normal in most pregnant females besides increased vasopressinase activity due to compensatory increase in pituitary gland production of $\mathrm{ADH}$. As a result of which polyuria is not usually encountered during pregnancy.

Gestational DI usually presents in third trimester of the pregnancy with polyuria, polydipsia (Brewster and Hayslett, 2005). It can occur in postpartum period especially if fluid intake of the patient is restricted which can result in severe hypernatremia (Sherer et al., 2003). It commonly occurs in women with multiple gestations due to higher placental volume and hence increased vasopressinase level. Diagnosis is made by inappropriately low urinary osmolality and high to normal plasma sodium concentration (Durr and Lindheimer, 1996; Davison et al., 1990). Hypernatremia is not usually encountered unless there is limited access to water (Brewster and Hayslett, 2005). Hypernatermia if present due to DI can be dangerous to both the mother and fetus. Gestational DI usually does not recur in subsequent pregnancies.

Treatment of Gestational DI includes administration of desmopressin which can be given either intranasal or subcutaneously. Desmopressin is a vasopressin analog which is resistant to degradation by placental vasopressinase. Usually a dose of $5-20 \mathrm{mcg}$

Intranasal or 2-5 mcg subcutaneously every 12-24 $\mathrm{h}$ is recommended for treatment of DI during pregnancy. dDAVP has no maternal or fetal adverse effects. Usually fluid restriction to $1 \mathrm{~L} /$ day is advised to avoid hyponatremia from dDAVP.

Subclinical central or nephrogenic DI: This type of diabetes insipidus occurs due to pre-existing insufficient vasopressin level or inability to respond to vasopressin due to various reasons (Iwasaki et al., 1991). Usually, these patients have polyuria and 
polydipsia prior to pregnancy and their symptoms continue after delivery of the baby. This type of diabetes insipidus recurs in future pregnancies.

Diabetes Insipidus associated with hepatic dysfunction: It is usually seen in women with preeclampsia, HELLP syndrome, or acute fatty liver of pregnancy and is caused by high circulating levels of vasopressinase (Katz and Bowes, 1987; Ferrara et al., 1980). These women have no prior history of water imbalance. The symptoms of polyuria and polydipsia respond well to administration of desmopressin.

Miscellaneous causes of diabetes insipidus: Some other causes of diabetes insipidus include absolute deficiency of vasopressin which can occur due to severe hemorrhage at delivery resulting in panhypopituitarism. There is concomitant deficiency of other pituitary hormones requiring hormone replacement therapy.

Acute kidney injury in pregnancy: Acute Kidney Injury (AKI) during pregnancy is very rare in developed countries at present. The low incidence in last 40 years is attributed to various factors like safe abortion, more common use of antibiotics and improvement in overall prenatal care. AKI is historically defined as deterioration of renal function over a span of few $h$ to days resulting in retention of nitrogenous products and inability of the kidneys to maintain fluid and electrolyte balance. Serum creatinine declines during pregnancy due to hypervolemia and hyperfiltration (Conrad, 1992). Serum creatinine is usually $40 \%$ lower during pregnancy compared to pregestation value. This fact should be kept in mind when dealing with a pregnant female with change in renal function during pregnancy. Acute Kidney Injury Network (AKIN) has classified kidney injury into three stages depending upon change in serum creatinine and urine output occurring over $48 \mathrm{~h}$ (Table 5). AKIN criterion has not been validated in pregnancy but is used to classify severity of AKI during pregnancy. Both MDRD and Cockcroft- Gault equation are inaccurate for calculation of GFR in pregnant females (Smith et al., 2008; Alper et al., 2007).

AKI in pregnancy can be divided into pre-renal, renal and post renal AKI. Prerenal AKI remains most common form of AKI during pregnancy and is usually caused by hypovolemia and decreased renal perfusion. This occurs with repeated vomiting due to hyperemesis gravidarum or acute pyelonephritis. If uncorrected, prerenal can progress to intrinsic renal disease resulting in ATN. Adequate and immediate correction of renal perfusion is of utmost importance to prevent intrinsic renal disease from prerenal causes. Diagnosis of prerenal AKI is based on history, physical examination and laboratory values. Urinalysis can help in differentiating various categories of AKI. Low urinary sodium (less than $20 \mathrm{meq} / \mathrm{L}$ ), low fractional excretion of sodium $(\mathrm{FeNa})<1 \%$, bland urine sediment and high blood urea nitrogen to creatinine ratio (normal ratio being 10-15:1) suggest diagnosis of pre-renal AKI in context of history and physical examination suggestive of hypovolemia.

Renal causes of AKI include acute tubular necrosis (ATN), bilateral cortical necrosis, thrombotic microanigopathies and glomerulonephritis/ vasculitis. ATN is seen mostly in women with sepsis from any cause. Sepsis can lead to hypotension, decreased renal perfusion and ATN. Common causes of sepsis during pregnancy include pyelonephritis, pneumonia, chorioamnionitis and septic abortion. Due to physiologic hydronephrosis during pregnancy, asymptomatic bacteriuria in pregnancy can be complicated by ascending infection and pyelonephritis (Connolly and Thorp, 1999). Glomerular filtration rate is usually decreased in pregnant females with pyelonephritis without sepsis (Whalley et al., 1975). Pyelonephritis is commonly caused by escherichia coli, proteus mirabilis and kebsiella. Occasionally ATN is seen in conjunction with septic abortion especially in underdeveloped countries due to lack of sterile equipment. Bacteria responsible for septic shock following septic abortion include e.coli, group B streptococcus, anaerobic streptococci, bacteroides species, clostridium species and enterococci (Sweet and Gibbs, 2009). Cortical necrosis is caused by obstetric hemorrhage which can occur at any stage of pregnancy but common during last trimester.

Thrombotic microangiopathies include preeclampsia/HELLP, Acute Fatty Liver of Pregnancy (AFLP), Hemolytic Uremic Syndrome (HUS/TTP) and Systemic Lupus Erythematosis (SLE) with the antiphospholipid antibody syndrome. These conditions are characterized by presence of hemolytic anemia, low platelets, hypoglycemia, high lactate dehydrogenase level and disseminated intravascular coagulation. It is usually difficult to distinguish these conditions clinically but both laboratory and clinical parameters help in making likely diagnosis.

Obstructive nephropathy is very rare in pregnancy and can be caused by compression of ureters by gravid uterus (Courban et al., 1997). This can occur frequently if pregnancy is multiple gestation pregnancy, polyhydramnios and pre-existing uterine fibroids. Maternal genitourinary anomalies or prior surgery can also predispose to obstructive uropathy, particularly in patients with unilateral kidney or collecting system (Fox et al., 1978). Nephrolithiasis in pregnancy can also give rise to AKI as incidence of stones in pregnancy is the same as in non pregnant females of reproductive age (Butler et al., 2000). These stones are 
composed of calcium oxalate and calcium phosphate in majority of cases. Nephrolithiasis can predispose to infection of urinary tract and induce premature labor. Ultrasound is the best way to diagnose obstruction and stones. The management of urinary calculi during pregnancy is conservative with adequate hydration, analgesics and antibiotics if complicated by superimposed infection. Thiazide diuretics and allopurinol are usually contraindicated during pregnancy. $24 \mathrm{~h}$ urine studies are done after delivery of the baby to delineate the underlying metabolic propensity to stone formation. Most stones pass spontaneously, but in some cases ureteral catheterization and ureteral stents may be needed to relieve obstruction. Treatment of AKI during pregnancy is usually supportive with prompt restoration of hypovolemia in volume depleted conditions and emergent delivery of baby later in pregnancy due to severe preeclampsia or HELLP syndrome. No specific therapy is effective in acute cortical necrosis. Plasmaphresis may be indicated in cases with TTP. Patients with HELLP or AFLP require prompt delivery. Both hemodialysis and peritoneal dialysis can be used in pregnancy if indicated. Sepsis responds to treatment with antibiotics and volume resuscitation. Survival is dependent on management and recovery of AKI (Gammill and Eyabalan, 2005).

In some cases of AKI during pregnancy, renal biopsy may need to be performed to diagnose underlying cause of AKI. Renal biopsy is safe during pregnancy. However, morbidity of this procedure during pregnancy may be high. Usually renal biopsy is indicated in pregnancy in patients with proteinuria not due to preclampsia and sudden deterioration of renal function before 32 weeks of gestation without any apparent cause because treatment of preclampsia is delivery of the baby and placenta whereas proteinuria unrelated to preeclampsia requires drug therapy and not delivery of the baby. Complication risk of renal biopsy including bleeding is $1.6-4.4 \%$ (Dennis et al., 1968). The mortality rate from renal biopsy remains very low (Packham and Fairley, 1987). Procurement rate of tissue is high in pregnancy and in $80 \%$ of patients a specific glomerulonephritis may be diagnosed (Lindheimer and Davison, 1987). Renal biopsy is performed under ultrasound guidance and histology may help direct disease specific treatment in $66-100 \%$ of cases.

D-chronic kidney disease in pregnancy: Pregnant women with pre-existing chronic kidney disease are at increased risk for adverse maternal and fetal outcomes. They can have rapid deterioration of renal function during pregnancy and can develop preeclampsia (Sanders and Lucas, 2001). The fetus is usually low birth weight, preterm delivery is common and perinatal mortality rate is high in patients with chronic kidney disease (Jones and Hayslett, 1996; Hou, 1999). The physiologic increase in renal blood flow and GFR expected during pregnancy is inadequate in patients with chronic kidney disease (Hou, 1999). The demand for increased renal blood flow during pregnancy may exacerbate renal damage in presence of chronic kidney disease. The degree of renal impairment affects maternal and fetal outcomes independent of the type of renal disease. Usually women with mild impairment of renal function $\left(\mathrm{Cr} 1.4 \mathrm{mg} \mathrm{dL}^{-1}\right.$ or less) and no proteinuria have better maternal and fetal outcomes than women with more severe renal impairment. Serum creatinine value greater than $2.0 \mathrm{mg} \mathrm{dL}^{-1}$ carries $30 \%$ risk of accelerated loss of renal function during and after pregnancy. Pregnant women with serum creatinine $>2.5 \mathrm{mg} \mathrm{dL}^{-1}$ have $70 \%$ chance of preterm delivery and $40 \%$ risk of preeclampsia (Sanders and Lucas, 2001; Jones and Hayslett, 1996). Women with autosomal dominant polycystic kidney disease with normal renal function usually complete pregnancy successfully (Vora et al., 2008). Patients with Systemic Lupus Erythematosis (SLE) and lupus nephritis can experience flare of lupus during pregnancy which can be associated with high risk of preterm delivery, spontaneous abortion and preeclampsia (Rahman et al., 1998; Khamashta and Hughes, 1996). This risk is greatest in patients with SLE with history of lupus nephritis and it is associated with high risk of preeclampsia. Lupus flare can be differentiated from preeclampsia based on presence of hematuria and red blood cell casts in urine in lupus nephritis whereas urine sediment is bland in preeclampsia patients. Serum complement levels are low in patients with lupus flare and normal in preeclampsia. Occasionally renal biopsy may be indicated for diagnosis of lupus flare from preeclampsia due to differences in treatment options. Lupus patients should be in complete remission and should receive minimal immunosuppression before planning pregnancy (Moroni and Ponticelli, 2005). Diabetes Mellitus remains the commonest cause of chronic kidney disease throughout the world (USRDS 2004). More women with diabetes mellitus become pregnant these days (Dunne, 2005). Like pregnant patients with SLE, diabetic women with or without nephropathy are at increased risk of adverse fetal and maternal outcomes during pregnancy as compared to no diabetic pregnant females (Dunne et al., 2003). This risk multiplies with presence of proteinuria and impaired renal function (Ekbom, 1999). Poor glycemic control before and during pregnancy has been associated with preeclampsia and serious fetal outcomes. Endocrinology consult is recommended before pregnancy (Suhonen et al., 2000). Pregnancy in diabetic woman with impaired renal function is associated with rapid decline in renal function especially in postpartum period. 
Am. Med. J. 3 (2): 147-160, 2012

Table 4: Acute Kidney Injury Network (AKIN) Criterion for Classification and Staging of Acute Kidney Injury (AKI)

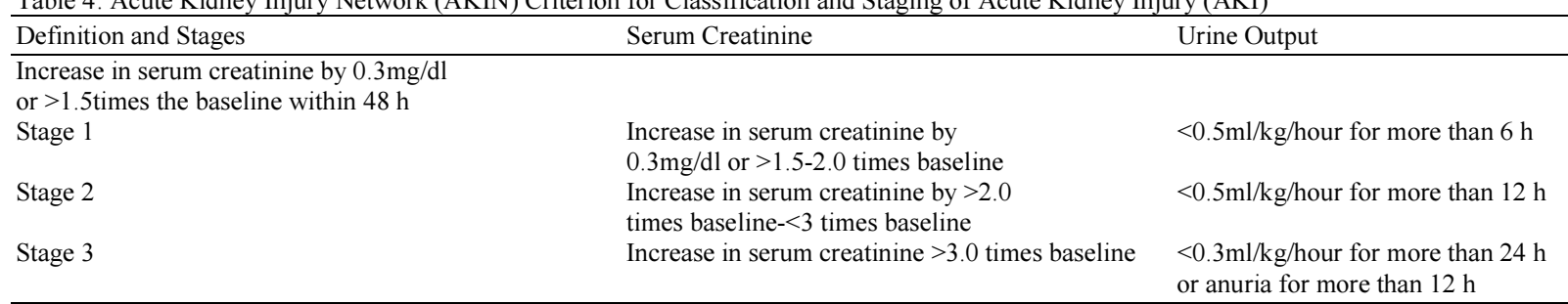

Aggressive blood pressure control before and after pregnancy may attenuate the postpartum decline in renal function (Rossing et al., 2002). ACE inhibitors and angiotensin receptor blockers are contraindicated during pregnancy due to risk of fetal malformations (Podymow et al., 2004). Therefore diabetic females with impaired renal function should be advised to postpone pregnancy until after kidney transplantation (Table 4).

E-Pregnancy in End Stage Renal Disease (ESRD): Patients with End Stage Renal Disease receiving chronic dialysis have problems with conception due to dysfunction of hypothalamus-pituitary-gonadal system. This may be due to disruption of gonadotropin releasing hormone from hypothalamus (Leavey and Weitzel, 2002). The incidence of pregnancy in female patients with ESRD receiving dialysis is $1.5-2.0 \%$ (Hou, 1994; Okundaye et al., 1998). Usually $50 \%$ of these pregnant females give birth to live infants, most of which are premature.

Management of a pregnant dialysis patients includes aggressive control of blood pressure, longer dialysis sessions $>20 \mathrm{~h}$ per week as it prolongs gestation and improves fetal outcome (Okundaye et al., 1998; Hou, 2003). Frequent adjustment of dry weights to allow for weight gain expected during pregnancy and avoidance of hypovolemia. Medications should be carefully reviewed to avoid drug toxicity to the fetus such as angiotensin converting enzyme inhibitors and angiotensin receptor blockers. Use of erythropoietin should be optimized to keep hemoglobin between 10$11 \mathrm{gm} / \mathrm{dl}$. Incidence of preeclampsia during pregnancy is difficult to determine due to inability to apply standard criterion used for non pregnant females. The nephrologist and obstetrician should work together closely for fetal well being. Pregnancy in women on peritoneal dialysis has similar outcome as patients on hemodialysis even though data is very limited (Jefferys et al., 2008).

F-renal transplantation and pregnancy: Renal transplantation can reverse infertility in patients on dialysis within six month. Transplantation induces restoration of hormonal imbalance back to normal in women of childbearing age group (Lessan-Pezeshki et al., 2004). Women with renal transplantation should postpone pregnancy for two years after transplantation to avoid morbidity and mortality ERAEDTAG, 2002. The transplant recipients with normal renal function, small stable doses of immunosuppression and no prior rejection episodes can consider conception as early as 1 year post transplant (McKay and Josephson, 2006). Renal allograft function remains stable during pregnancy provided baseline graft function is normal and significant hypertension is not present ERAEDTAG, 2002.

The transplant recipient is at risk of various complications during pregnancy including infections which can be both bacterial and viral. The common infections seen are cytomegalovirus, herpes simplex and toxoplasmosis, bacterial urinary tract infections which can affect fetus. Hypertension is commonly encountered from use of calcineurin inhibitors for immunosuppression. Preeclampsia can complicate 25$30 \%$ of pregnancies in renal transplant recipients (Armenti et al., 2006; Gutierrez et al., 2005). One should monitor immunosuppressive drug therapy closely during pregnancy due to their effects on fetus, altered absorption and metabolism due to change in renal hemodynamics (Garcia-Donaire et al., 2005). Angiotensin converting enzyme inhibitors and angiotensin receptor blockers should be discontinued in all pregnant women due to their effects on the fetus. Sirolimus is contraindicated during pregnancy due to teratogenecity (Danesi and Tacca, 2004). MMF is associated with developmental toxicity to the fetus, malformations and can be associated with spontaneous abortion (Ray et al., 2004). Table 5 gives an overview of various immunosuppressive drugs in renal transplant recipients and their use during pregnancy.

Data on fetal outcome in renal transplant recipients is derived from various registries. $22 \%$ of pregnancies in transplant recipients end in first trimester due to combination of miscarriage or elective abortions (Armenti et al., 2006). Those which continues on result in successful outcome in $90 \%$ of cases. There is usually risk of low birth weight or preterm delivery in these pregnancies (Armenti et al., 2006; Gutierrez et al., 2005). Vaginal delivery is safe and cesarean section in performed only for obstetrical indications in these patients. 
Table 5: Immunosuppressive drugs in pregnancy

\begin{tabular}{|c|c|c|c|}
\hline Drug & FDA category & Use in pregnancy & Precautions during pregnancy \\
\hline Prednisone & $\mathrm{B}$ & $\begin{array}{l}\text { Used safely in doses of } 5-10 \mathrm{mg} / \text { day and } \\
\text { can be given in high doses at delivery time }\end{array}$ & Can cause fetal growth retardation \\
\hline Cyclosporin & $\mathrm{C}$ & Can be used at low doses & $\begin{array}{l}\text { Requires frequent monitoring of levels } \\
\text { due to decreased GI absorption and } \\
\text { metabolism. Can cause fetal growth retardation }\end{array}$ \\
\hline Tacrolimus & $\mathrm{C}$ & $\begin{array}{l}\text { Can be used at low doses although } \\
\text { less date available }\end{array}$ & Frequent monitoring of the level required \\
\hline Azathioprine & $\mathrm{D}$ & Safe at doses $<2 \mathrm{mg} / \mathrm{kg} /$ day & $\begin{array}{l}\text { can be associated with fetal growth retardation } \\
\text { at high doses }\end{array}$ \\
\hline Sirolimus & $\mathrm{C}$ & $\begin{array}{l}\text { Teratogenic in animals but no } \\
\text { human studies on safety }\end{array}$ & $\begin{array}{l}\text { Should be discontinued in pregnant } \\
\text { transplant patients }\end{array}$ \\
\hline Mycophenalate mofetil & $\mathrm{D}$ & $\begin{array}{l}\text { Cannot be used in pregnancy due to } \\
\text { teratogenecity in both animals and humans }\end{array}$ & Contraindicated for use in pregnancy \\
\hline Antithymocyte globulin & $\mathrm{C}$ & No animal data on safety & No human data on safety \\
\hline OKT3 & $\mathrm{C}$ & Safety data limited documenting safety & Limited safety data confined to few case reports \\
\hline
\end{tabular}

Renal disorders in non pregnant females: Females can suffer from any renal disorder in non pregnant state which encompasses acute kidney injury in non pregnant condition due to various insults, chronic kidney disease due to systemic diseases or nephrotic syndrome due to various glomerular diseases. This section focuses on renal issues seen due to various gynecologic problems in females.

A-uterine fibroids: Uterine fibroids are the most common pelvic tumors in females (Baird et al., 2003; Buttram and Reiter, 1981). They are benign monoclonal tumors arising from smooth muscles of the myometrium. These tumors can be intramural, sub mucosal, subserosal and cervical in location. They occur in females of reproductive age and present with various symptoms, e.g., abnormal uterine bleeding, pelvic pain or pressure or reproductive problems. Myomas are clinically apparent in approximately 12$25 \%$ of females of reproductive age (Downes et al., 2010). Rarely, uterine fibroids can affect urinary tract and give rise to various renal problems. To date, Urinary Retention (UR), Acute Kidney Injury (AKI), Chronic Kidney Disease (CKD) and Hypertension have been reported due to uterine fibroids.

Urinary Retention (UR): Uterine myomas can cause compression of the urinary bladder and urethra due to mass effect. Urinary retention can be acute or chronic asymptomatic (Novi et al., 2004; Kuroda et al., 1999; Yang and Huang, 2002). This can occur both in non pregnant and pregnant conditions. In normal pregnancy, the uterus may partially obstruct the ureters at pelvic brim which results in dilatation of ureters without worsening renal function (2). In myomatous uterus, the uterus is irregularly shaped and can cause specific symptoms due to pressure from myomas at specific locations. Anteriorly situated fibroids can cause direct pressure on urinary bladder. A fibroid situated in posterior part of the uterus can push the entire uterus forward and cause compression of the urinary bladder. Urinary retention due to fibroids results from displacement of the cervix superiorly and anteriorly in supine position. It causes compression of the lower part of urinary bladder leading to obstruction of the internal urethral meatus.

Acute Kidney Injury (AKI): AKI due to uterine fibroid occurs very rarely. It can be seen in both in pregnant and non pregnant women with pre-existing fibroids (Brandes and Fritsche, 1991; Elia et al., 1982). AKI can occur due to obstruction of the urinary tract. Pregnancy results in growth of myoma under hormonal changes. Impaction of a retroverted gravid uterus can occur in pregnancy complicated by uterine fibroids which can result in formation of pelvic adhesions and contracted pelvis.

In nonpregnant females, urinary retention can result from various causes like urinary tract infection, medications, poor detrusor contractility. Fibroids cause mechanical compression of the bladder resulting in outflow obstruction and urinary retention. Diagnosis is made by urodynamic assessment and neurophysiological evaluation of the prudendal and sacral nerves. Treatment includes immediate relief of obstruction by catheterization. Ultimately, patients need myomectomy or hysterectomy or uterine artery embolization (UAE). UAE may cause immediate relief of symptoms of retention before any appreciable change in size of the myoma (Kagan and Mich, 2008). This could be due to relief of ischemia due to hypervascular fibroids on surrounding organs (Fig. 1).

Chronic kidney disease: Chronic Kidney Disease (CKD) due to uterine fibroid has been described in the literature (Bansal et al., 2009). CKD from uterine fibroids results from chronic obstruction due to compression of urinary tract by the uterine fibroids. The site and degree of urinary tract obstruction 
commonly depend on number and location of fibroids. Cervical fibroids are commonly associated with obstruction than fundal or central fibroids. Usually hysterectomy is indicated for symptomatic cure although it may not be the best choice in women who have not completed their family. Myomectomy and uterine artery embolization are other choices for therapy of uterine fibroids. Myomectomy is associated with high risk of bleeding and preceding uterine artery embolization may help to reduce size of the fibroids and make myomectomy easier.

Hypertension: Secondary Hypertension is another complication of myomas. It results from development of hydronephrosis caused by large myomas. It can occur in both pregnant and non pregnant females (Satin et al., 1993) and is usually relieved by placement of nephrostomy tubes. Animal experiments have shown that Hypertension is related to degree of hydronephrosis, is salt sensitive and rennin levels are increased in hydronephrotic rats as compared to control group (Carlstrom et al., 2006). Other studies have shown that ureteral obstruction can cause renal injury with subsequent fibrosis via oxidative stress and decreased Nitric oxide activity which leads to increased Tubuloglomerular Feedback (TGF) and hypertension. Other suggested mechanisms to hypertension include increased intra-renal pressure with compression of the intrarenal veins against renal capsule which leads to decreased GFR. This results in compensatory increased proximal tubular reabsorption of sodium and water causing increased plasma volume and hence hypertension.

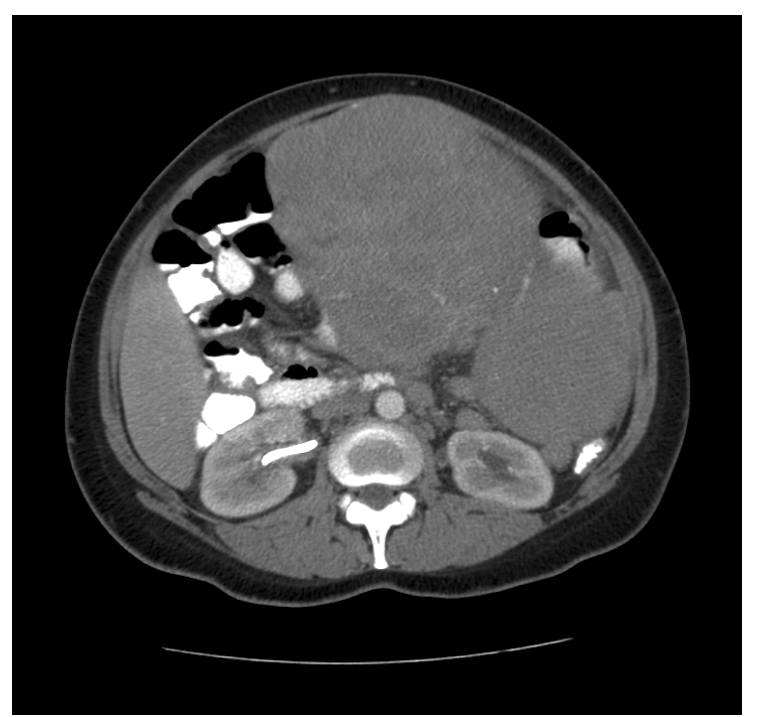

Fig. 1: This shows a large uterus with fibroids and right sided hydronephrosis
Malignancies of female reproductive system: Female reproductive system malignancies like uterine and cervical cancers can cause similar spectrum of renal problems in affected patients as caused by uterine fibroids.

\section{CONCLUSION}

Renal disorders related to female reproductive system are commonly encountered by nephrologists during practice especially during pregnancy. A detailed knowledge of these problems help manage these patients better and reduce complication rate.

\section{REFERENCES}

ACOG, 2002. ACOG practice bulletin. Diagnosis and management of preeclampsia and eclampsia. Int. J. Gynaecol. Obstet., 77: 67-75. PMID: 12094777

Akbari, A., P. Wilkes, M. Lindheimer, N. Lepage and G. Filler, 2007. Reference intervals for anion gap and strong ion difference in pregnancy: A pilot study. Hypertens Pregnancy, 26: 111-119. PMID: 17454223

Alper, A.B., Y. Yi, L.S. Webber, G . Pridjian and A.A. Mumuney et al., 2007. Estimation of glomerular filtration rate in preeclamptic patients. Am. J. Perinatol., 24: 569-574. PMID: 17909992

Armenti, V.T., J.A. Daller, S. Constantinescu, P. Silva and J.S. Radomski et al., 2006. Report from the national transplantation pregnancy registry: outcomes of pregnancy after transplantation. Clin. Transpl., 57-70. PMID: 18368705

Bailey, R.R. and G.L. Rolleston, 1971. Kidney length and ureteric dilatation in the puerperium. J. Obstet. Gynaecol. Br. Commonw., 78: 55-61. PMID: 5557675

Baird, D.D., D.B. Dunson, M.C. Hill, D. Cousins and J.M. Schectman, 2003. High cumulative incidence of uterine leiomyoma in black and white women: ultrasound evidence. Am. J. Obstet. Gynecol., 188: 100-1007. PMID: 12548202

Bansal, T., P. Mehrotra, D. Jayasena, S. Okolo and W. Yoong et al., 2009. Obstructive nephropathy and chronic kidney disease secondary to uterine leiomyomas. Arch. Gynecol. Obstet., 279: 785 788. PMID: 18818940

Bdolah, Y., C. Lam, A. Rajakumar, V. Shivalingappa and W. Mutter et al., 2008. Twin pregnancy and the risk of preeclampsia: Bigger placenta or relative ischemia? Am. J. Obstet. Gynecol., 198:: 428-428. PMID: 18191808

Bellamy, L., J.P. Casas, A.D. Hingorani and D.J. Williams, 2007. Pre-eclampsia and risk of cardiovascular disease and cancer in later life: systematic review and meta-analysis. BMJ, 335: 974-974. PMID: 17975258 
Beydoun, S.N., 1985. Morphologic changes in the renal tract in pregnancy. Clin. Obstet. Gynecol., 28: 249256. PMID: 4017319

Bombrys, A.E., J.R. Barton, E.A. Nowacki, M. Habli and L. Pinder et al. 2008. Expectant management of severe preeclampsia at less than 27 weeks' gestation: Maternal and perinatal outcomes according to gestational age by weeks at onset of expectant management. Am. J. Obstet. Gynecol., 199: 241-246. PMID: 18771971

Brandes, J.C. and C. Fritsche, 1991. Obstructive acute renal failure by a gravid uterus: A case report and review. Am. J. Kidney Dis., 18: 398-401. PMID: 1882835

Brewster, U.C. and J.P. Hayslett, 2005. Diabetes insipidus in the third trimester of pregnancy. Obstet. Gynecol., 105: 1173-1176. PMID: 15863571

Butler, E., S.M. Cox, E.G. Eberts F.G.Cunningham 2000. Symptomatic nephrolithiasis complicating pregnancy. Obstet. Gynecol., 96: 753-756. PMID: 11042313

Buttram, V.C. Jr. and R.C. Reiter, 1981. Uterine leiomyomata: etiology, symptomatology and management. Fertil Steril., 36: 433-445. PMID: 7026295

Carlstrom, M., N. Wahlin, J. Sallstrom, O. Skott and R. Brown et al., 2006. Hydronephrosis causes salt sensitive hypertension in rats. J. Hypertension., 24: 1437-1443. PMID: 16794495

Chambers, J.C., M.D. Chambers, M.R.C.P.L. Fusi, M.D. Frcog and S. Iqbal et al., 2001. Association of maternal endothelial dysfunction with preeclampsia. JAMA, 285: 1607-1612. DOI: 10.1001/jama.285.12.1607

Connolly, A. and J.M. Thorp, 1999. Urinary tract infections in pregnancy. Urol. Clin. North Am., 26: 779-787.

Conrad, K., 1992. Renal changes in pregnancy. Urol. Ann., 6: 313-340.

Cote, A.M., T. Firoz, A. Mattman, E.M. Lam and V.P. Dadelszen et al., 2008. The 24-hour urine collection: Gold standard or historical practice? Am. J. Obstet. Gynecol., 625: 1-6. PMID: 18718568

Courban, D., S. Blank, M.A. Harris, J. Bracy and P. August 1997. Acute renal failure in the first trimester resulting from uterine leiomyomas. Am. J. Obstet. Gynecol., 177: 472-473. PMID: 9290476

Danesi, R. and M.D. Tacca, 2004. Teratogenesis and immunosuppressive treatment. Transplant Proc., 36: 705-707. PMID: 15110638
Davison, J.M. and W. Dunlop, 1980. Renal hemodynamics and tubular function normal human pregnancy. Kidney Int., 18: 152-161. PMID: 7003196

Davison, J.M., E.A. Shiells, P.R. Philips and M.D. Lindheimer, 1990. Influence of humoral and volume factors on altered osmoregulation of normal human pregnancy. Am. J. Physiol., 258: 900-907. PMID: 2330984

Dennis, E.J., F.A. McIver and C.M. Smythe, 1968. Renal biopsy in pregnancy. Clin. Obstet. Gynecol., 11: 473-486. PMID: 4879375

Dolea, C. and C. AbouZahr, 2003. Global burden of hypertensive disorders of pregnancy in the year 2000. World Health Organization, Geneva.

Downes, E., V. Sikirica, J. Gilabert-Estelles, S.C. Bolge and S.L. Dodd et al., 2010. The burden of uterine fibroids in five European countries. Eur. J. Obstet. Gynecol. Reprod. Biol., 152: 96-102. PMID: 20598796

Dunne, F., 2005. Type 2 diabetes and pregnancy. Semin Fetal Neonatal Med., 10: 333-339.

Dunne, F., P. Brydon, K. Smith, H. Gee 2003. Pregnancy in women with type 2 diabetes: 12 years outcome data 1990-2002. Diabet. Med., 20: 734-738. PMID: 12925053

Durr, J.A. and M.D. Lindheimer, 1996. Diagnosis and management of diabetes insipidus during pregnancy. Endocr. Pract., 2: 353-361. PMID: 15251517

Durr, J.A., 1987. Diabetes insipidus in pregnancy. Am. J. Kidney Dis. 9: 276-283. PMID: 3554998

Durr, J.A., J.G. Hoggard, J.M. Hunt and R.W. Schrier 1987. Diabetes insipidus in pregnancy associated with abnormally high circulating vasopressinase activity. N. Engl. J. Med., 316: 1070. PMID: 3561459

Ekbom, P., 1999. Pre-eclampsia in Diabetic Pregnancy Study Group: Pre-pregnancy microalbuminuria predicts pre-eclampsia in insulin-dependent diabetes mellitus. Lancet, 353: 377-330. DOI: 10.1016/S0140-6736(05)74949-7

Elia, D.F.L., R.E. Brennan and P.K. Brownstein, 1982. Acute renal failure secondary to ureteral obstruction by a gravid uterus. J. Urol., 128: 803804. PMID: 7143605

Elsheikh, A., G. Creatsas, G. Mastorakos, S. Milingos and D. Loutradis et al., 2001. The reninaldosterone system during normal and hypertensive pregnancy. Arch. Gynecol. Obstet., 264: 182-185. PMID: 11205704

Esser, S., K. Wolburg, H. Wolburg, G. Breier and T. Kurzchalia et al., 1998. Vascular endothelial growth factor induces endothelial fenestrations in vitro. J. Cell. Biol., 140: 947-959. PMID: 9472045 
Ferrara, J.M., R. Malatesta and E. Kemmann, 1980. Transient nephrogenic diabetes insipidus during toxemia in pregnancy. Diagn Gynecol. Obstet., 2: 227. PMID: 7439021

Fox, J., M. Katz, S.A. Klein and B.K. Young, 1978. Sudden anuria in a pregnant woman with a solitary kidney. Am. J. Obstet. Gynecol., 132: 583-585. PMID: 717462

Gammill, H.S. and A. Eyabalan, 2005. Acute renal failure in pregnancy. Crit. Care Med., 33: 372-384. PMID: 16215361

Garcia-Donaire, J.A., M. Acevedo, M.J. Gutierrez, M.J. Manzanera and E. Oliva et al., 2005. Tacrolimus as basic immunosuppression in pregnancy after renal transplantation: A single-center experience. Transplant Proc., 37: 3754-3755. PMID: 16386528

Geller, D.S., A. Farhi, N. Pinkerton, M. Fradley and M. Moritz et al., 2000. Activating mineralocorticoid receptor mutation in hypertension exacerbated by pregnancy. Science, 289: 119-123. PMID: 10884226

Gutierrez, M.J., M. Acebedo-Ribo, J.A. GarcíaDonaire, M.J. Manzanera and A. Molina et al., 2005. Pregnancy in renal transplant recipients. Transplant. Proc., 37: 3721-3722. DOI: 10.1016/j.transproceed.2005.09.175

Hayashida, M., N. Watanabe, H. Imamura, S. Kumazaki and H. Kitabayashi et al., 2005. Congenital solitary kidney with renovascular hypertension diagnosed by means of captoprilenhanced renography and magnetic resonance angiography. Int. Heart J., 46: 347-353. PMID: 15876820

Heidrick, W.P., R.F. Mattingly and J.R. Amberg, 1967. Vesicoureteral reflux in pregnancy. Obstet. Gynecol., 29: 571-578.

Helewa, M.E., R.F. Burrows, J. Smith, K. Williams and P. Brain, 1997. Report of the Canadian Hypertension Society Consensus Conference: 1 . Definitions, evaluation and classification of hypertensive disorders in pregnancy. CMAJ, 157: 715-725. PMID: 9307560

Hjartardottir, S., B.G. Leifsson, R.T. Geirsson and V. Steinthorsdottir, 2006. Recurrence of hypertensive disorder in second pregnancy. Am. J. Obstet. Gynecol., 194: 916-920. PMID: 16580276

Hou, S., 1999. Pregnancy in chronic renal insufficiency and end-stage renal disease. Am J. Kidney Dis., 33: 235-252.

Hou, S., 2003. Editorial focus dialysis and pregnancy pregnancy in dialysis patients where do we go from here.? Semin Dial., 16: 376-378. DOI: 10.1046/j.1525-139X.2003.16083.x

Hou, S.H., 1994. Frequency and outcome of pregnancy in women on dialysis. Am. J. Kidney Dis., 23: 6063. PMID: 8285199
Hutchison, J.A., et al.2003. National Institute of child health and human development maternal-fetal medicine Units Network. Semin Perinatol., 27: 239-239.

Iwasaki, Y., Y. Oiso, K. Kondo, S. Takagi and K. Takatsuki et al., 1991. Aggravation of subclinical diabetes insipidus during pregnancy. N. Engl. J. Med., 324: 522-526. PMID: 1992305

Jefferys, A., K. Wyburn, J. Chow, B Cleland and A. Hennessy, 2008. Peritoneal dialysis in pregnancy: A case series. Nephrology, 13: 380-383. DOI: 10.1111/j.1440-1797.2008.00938.x

Jim, B., P. J. Louis, A. Qipo, D. Garry and S. Mian, et al., 2012. Podocyturia as a diagnostic marker for preeclampsia amongst high-risk pregnant patients. J. Pregnancy, 2012: 1-5. DOI: $10.1155 / 2012 / 984630$

Jones, D.C. and J.P. Hayslett, 1996. Outcome of pregnancy in women with moderate or severe renal insufficiency. N. Engl. J. Med., 335: 226-232. DOI: $10.1056 /$ NEJM199607253350402

Kagan, A.E. and T.G. Mich, 2008. Fibroid-induced acute urinary retention: Treatment by uterine artery embolization. Int. Urogynaecol. J., 19: 161-165. PMID: 17909691

Katz, V.L. and W.A. Bowes, 1987. Transient diabetes insipidus and preeclampsia. South Med. J., 80: 524-525.

Khamashta, M.A. and G.R. Hughes, 1996. Pregnancy in systemic lupus erythematosus. Curr. Opin. Rheumatol., 8: 424-429. PMID: 8941445

Khan, F., J.J. Belch, M. MacLeod and G. Mires, 2005. Changes in endothelial function precede the clinical disease in women in whom preeclampsia develops. Hypertension. 46: 1123-1128. DOI: 10.1161/01.HYP.0000186328.90667.95

Kuroda, D., M. Gotoh, K. Okamura, Y. Ono and S. Ohshima et al., 1999. Three cases of urinary retention caused by uterine leiomyoma. Hinyokika Kiyo, 45: 115-117. PMID: 10212785

Ray, C.L., A. Coulomb, E. Elefant, R. Frydman and F. Audibert, 2004. Mycophenolate mofetil in pregnancy after renal transplantation: A case of major fetal malformations. Obstet. Gynecol., 103: 1091-1094. PMID: 15121619

Leavey, S.F. and W.F. Weitzel, 2002. Endocrine abnormalities in chronic renal failure. Endocrinol. Metab. Clin. North Am., 31: 107-119. PMID: 12055983

Lessan-Pezeshki, M., S. Ghazizadeh, M.R. Khatami, M. Mahdavi and E. Razeghi et al., 2004. Fertility and contraceptive issues after kidney transplantation in women. Transplant. Proc., 36: 1405-1406. PMID: 15251344 
Lim, V.S., A.I. Katz and M.D. Lindheimer, 1976. Acid base regulation in pregnancy. Am. J. Physiol., 231: 1764-1769. PMID: 990114

Lind, T., K.A. Godfrey, H. Otun and P.R. Philips, 1984. Changes in serum uric acid concentration during normal pregnancy. Br. J. Obstet. Gynaecol., 91: 128-132. PMID: 6696858

Lindheimer, M.D. and J.M. Davison, 1987. Renal biopsy during pregnancy: to b . . or not to b . .?" Br. J. Obstet. Gynaecol., 94: 932-934. DOI: 10.1111/j.1471-0528.1987.tb02265.x

Lindheimer, M.D., W.M. Barron and J.M. Davison 1991. Osmotic and volume control of vasopressin release in pregnancy. Am. J. Kidney Dis., 17: 105. PMID: 1992649

Lindheimer, M.D., W.M. Barron and J.M. Davison, 1989. Osmoregulation of thirst and vasopressin release in pregnancy. Am. J. Physiol., 257: 159-169.

Magee, L.A., M.P. Ornstein and P.V. Dadelszen, 1999. Fortnightly review: Management of hypertension in pregnancy. BMJ. 318: 1332-1336.

Mattingly, R.F. and H.I. Borkowf, 1978. Clinical implications of ureteral reflux in pregnancy. Clin. Obstet. Gynecol., 21: 863-873. PMID: 699418

McDonald, S.D., A .Malinowski, Q. Zhou, S. Yusuf and P.J. Devereaux, 2008. Cardiovascular sequelae of preeclampsia/eclampsia: A systematic review and meta-analyses. Am. Heart J., 156: 918-930. PMID: 19061708

McKay, D.B. and M.A. Josephson, 2006. Pregnancy in recipients of solid organs--effects on mother and child. N. Engl. J. Med., 354: 1281-1293. PMID: 16554530

Meekins, J.W., R. Pijnenborg, M. Hanssens, I.R. McFadyen and A. Asshe, 1994. A study of placental bed spiral arteries and trophoblast invasion in normal and severe pre-eclamptic pregnancies. Br. J. Obstet. Gynecol., 101: 669-674. PMID: 7947500

Moroni, G. and C. Ponticelli, 2005. Pregnancy after lupus nephritis. Lupus, 14: 89-94. PMID: 15732295

Novi, J.M., A. Shaunik, B.H. Mulvihill and M.A. Morgan, 2004. Acute urinary retention caused by a uterine leiomyoma: A case report. J. Reprod. Med., 49: 131-132. PMID: 15018444

Odendaal, H.J., R.C. Pattinson, R. Bam and T.J. Kotze 1990. Aggressive or expectant management for patients with severe preeclampsia between 28-34 weeks' gestation: A randomized controlled trial. Obstet. Gynecol., 76: 1070-1075. PMID: 2234715

Okundaye, I., P. Abrinko and S. Hou, 1998. Registry of pregnancy in dialysis patients. Am. J. Kidney Dis., 31: 766-773. PMID: 9590185
Packham, D. and K.F. Fairley, 1987. Renal biopsy: Indications and complications in pregnancy. Br. J. Obstet. Gynaecol., 94: 935-939. DOI: 10.1111/j.1471-0528.1987.tb02266.x

Podymow, T., P. August and J.G. Umans, 2004. Antihypertensive therapy in pregnancy. Semin Nephrol., 24: 616-625.

Rahman, P., D.D. Gladman and M.B. Urowitz, 1998. Clinical predictors of fetal outcome in systemic lupus erythematosus. J. Rheumatol., 25: 15261530. PMID: 9712095

Rasmussen, P.E. and F.R. Nielsen, 1988. Hydronephrosis during pregnancy: A literature survey. Eur. J. Obstet. Gynecol. Reprod. Biol., 27: 249-259. PMID: 3280355

Reubinoff, B.E. and J.G. Schenker, 1991. HELLP syndrome--a syndrome of hemolysis, elevated liver enzymes and low platelet count--complicating preeclampsia-eclampsia. Int. J. Gynaecol. Obstet., 36: 95-102. DOI: 10.1016/0020-7292(91)90762-T,

Robertson, W.B., I. Brosens and H.G. Dixon, 1967. The pathological response of the vessels of the placental bed to hypertensive pregnancy. J. Pathol. Bacteriol., 93: 581-592. PMID: 6054058

Rossing, K., P. Jacobsen, E. Hommel, E. Mathiesen and A. Svenningsen et al., 2002. Pregnancy and progression of diabetic nephropathy. Diabetol., 45: 36-41. PMID: 11845221

Saftlas, A.F., D.R. Olson, A.L. Franks, H.K. Atrash and R. Pokras, 1990. Epidemiology of preeclampsia and eclampsia in the United States, 1979-1986. Am. J. Obstet. Gynecol., 163: 460-465. PMID: 2386132

Sanders, C.L. and M.J. Lucas, 2001. Renal disease in pregnancy. Obstet. Gynecol. Clin. North Am., 28: 593-600.

Satin, A.J., G.L. Seiken and F.G. Cunningham, 1993. Reversible hypertension in pregnancy caused by obstructive uropathy. Obstet. Gynecol., 81: 823825. PMID: 8469485

Saudan, P., M.A. Brown, M.L. Buddle and M. Jones, 1998. Does gestational hypertension become preeclampsia? Br. J. Obstet. Gynaecol., 105: 11771184. PMID: 9853766

Shembrey, M.A. and A.D. Noble, 1995. An instructive case of abdominal pregnancy. Aust. NZ J. Obstet. Gynaecol., 35: 220-221. PMID: 7677698

Sherer, D.M., J. Cutler, P. Santoso and A.S. Abulafia, 2003. Severe hypernatremia after cesarean delivery secondary to transient diabetes insipidus of pregnancy. O Obstet. Gynecol., 102: 1166-1168. PMID: 14607044 
Simon, M., W. Rockl, C. Hornig, E.F. Gröne and H. Theis, et al., 1998. Receptors of vascular endothelial growth factor/vascular permeability factor (VEGF/VPF) in fetal and adult human kidney: Localization and VEGF binding sites. J. Am. Soc. Nephrol., 9: 1032-1044. PMID: 9621286

Smith, M.C., P. Moran M.K. Ward and J.M. Davison 2008. Assessment of glomerular filtration rate during pregnancy using the MDRD formula. BJOG, 115: 109-112. PMID: 17970797

Suhonen, L., V. Hiilesmaa and K. Teramo, 2000. Glycaemic control during early pregnancy and fetal malformations in women with type I diabetes mellitus. Diabetologia, 43: 79-82. PMID: 10663219

Sweet, R. and R. Gibbs, 2009. Infectious Diseases of the Female Genital Tract. 5th Edn., Lippincott Williams and Wilkins, Philadelphia, ISBN-10: 0781778158, pp: 480.

Thorp, J.M., J. Norton, P.A. Wall L.L. Kuller and J.A. Eucker, 1999. Urinary incontinence in pregnancy and the puerperium: A prospective study. Am. J. Obstet. Gynecol., 181: 266-273. PMID: 10454667

Tuffnell, D.J., D. Jankowicz, S.W. Lindow, G. Lyons and G.C. Mason et al., 2005. Outcomes of severe pre-eclampsia/eclampsia in Yorkshire 1999/2003. BJOG, 112: 875-880. PMID: 15957986

USRDS, 2004. Annual data report. Bethesda: National Institutes of Health.

Vora, N., R. Perrone and D.W. Bianchi, 2008. Reproductive issues for adults with autosomal dominant polycystic kidney disease. Am. J. Kidney Dis., 51: 307-318. DOI: 10.1053/j.ajkd.2007.09.010

Wallis, A.B., A.F. Saftlas, J. Hsia and H.K. Atrash, 2008. Secular trends in the rates of preeclampsia, eclampsia and gestational hypertension, United States. 1987-2004. Am. J. Hypertens, 21: 521-526. PMID: 18437143

Wesnes, S.L., G. Rortveit and B.K.S. Hunskaar, 2007. Urinary incontinence during pregnancy. Obstet. Gynecol., 109: 922-928. DOI: 10.1097/01.AOG.0000257120.23260.00
Whalley, P., F. Cunningham and F. Martin, 1975. Transient renal dysfunction associated with acute pyelonephritis of pregnancy. Obstet. Gynecol., 46: 174-177. PMID: 1097976

Wolf, D.F., D.C. Wolf-Peeters, I. Brosens and W.B. Robertson, 1980. The human placental bed: Electron microscopic study of trophoblastic invasion of spiral arteries. Am. J. Obstet. Gynecol., 137: 58-70. PMID: 7369289

Wolf, M., A. Shah, C. Lam A. Martinez and K.V. Smirnakis et al., 2005. Circulating levels of the antiangiogenic marker sFLT-1 are increased in first versus second pregnancies. Am. J. Obstet. Gynecol., 193: 16-22. PMID: 16021053

Wyckoff, J.A., E.W. Seely, S. Hurwitz, B.F. Anderson and R.P. Lifton et al., 2000. Glucocorticoidremediable aldosteronism and pregnancy. Hypertension, 35: 668-672. PMID: 10679515

Yancopoulos, G.D., S. Davis, N.W. Gale, J.S. Rudge and S.J. Wiegand et al., 2000. Vascular-specific growth factors and blood vessel formation. Nature.,407: 242-248. PMID: 11001067

Yang, J.M. and W.C. Huang, 2002. Sonographic findings of acute urinary retention secondary to impacted pelvic mass. J. Ultrasound Med., 21: 1165-1169. PMID: 12369672

Yoder, S.R., L.L. Thornburg and J.D. Bisognano, 2009. Hypertension in pregnancy and women of childbearing age. Am. J. Med., 122: 890-895. PMID: 19786154

Zhou, Y., M. McMaster, K. Woo, M. Janatpour and J. Perry, et al., 2002. Vascular endothelial growth factor ligands and receptors that regulate human cytotrophoblast survival are dysregulated in severe preeclampsia and hemolysis, elevated liver enzymes and low platelets syndrome. Am. J. Pathol., 160: 1405-1423. PMID: 11943725

Zhou, Y., S.J. Fisher, M. Janatpour, O. Genbacev and E. Dejana et al., 1997. Human cytotrophoblasts adopt a vascular phenotype as they differentiate: A strategy for successful endovascular invasion? J. Clin. Invest., 99: 2139-2151. PMID: 9151786 